\title{
Control and Implementation of Single-Inverter Microgrid
}

\author{
Mehdi Moradian, Milad Moradian \\ Roham Sanat Engineering Co., Tehran, Iran \\ Email: M_Moradian86@yahoo.com
}

How to cite this paper: Moradian, M. and Moradian, M. (2019) Control and Implementation of Single-Inverter Microgrid. Smart Grid and Renewable Energy, 10, 29-41. https://doi.org/10.4236/sgre.2019.102003

Received: June 12, 2018

Accepted: February 25, 2019

Published: February 28, 2019

Copyright $\odot 2019$ by author(s) and Scientific Research Publishing Inc. This work is licensed under the Creative Commons Attribution International License (CC BY 4.0).

http://creativecommons.org/licenses/by/4.0/

\begin{abstract}
In this paper, simulation and implementation way for practical control of Single Inverter Microgrid (SIMG) is presented. This system is equipped by solar system, wind energy conversion system (WECS), and microturbine system. Each DG's has controlled independently. This is a kind of decentralize control because each DG's has difference controller. Control of Microgrid (MG) during both grid tie and islanding modes is presented. Solar system and WECS are modeled based on santerno products. This system is compared with three inverter MGs with Centralize control strategy. Controlled signals show that SIMG is more reliable and economical. THD is improved and strategy is simplified for SIMG.
\end{abstract}

\section{Keywords}

Single Inverter Microgrid, Solar System, Wind Energy Conversion System, Microturbine, Buck and Boost Chopper

\section{Introduction}

Renewable energy emerges as an alternative way of generating clean energy. As a result, increasing the use of "green" energy benefits the global environment, making it global concern. This topic relies on a variety of manufacturing and installation industries for its development. As a solution, continuously small and smart grid energy systems appear including renewable energy resources (RES), micro-generators, small energy storage systems, critical and noncritical loads, forming among them a special type of distributed generation system called the Microgrid.

Microgrids knowledge presents a wide range of solution for all of traditional grids problems such as: energy management, system stability, voltage quality, active and reactive power flow control, islanding detection, grid synchronization, 
and system recovery, all together and provides optimal use of small scale energy generation interaction, increases the penetration of RES, and operates in both grid connected or in autonomous modes. These small but smart grids present a new paradigm for low voltage distribution systems, in which a multilevel control system must be performed in order to ensure the proper operation of the MG [1].

Recent advances using smart grid technology to maximize operations efficiency, monitoring and supervisory control, power management, and utility grid supplying, make this kind of system a suitable solution for decentralizing the electricity production. Thus, the study of these small grids is imperative because they are helpful to fulfill the maximization of the following issues:

- Efficiency and demand trends involving technological changes.

- Advanced energy storage systems.

- Reduced system restoration time due to transition between the utility grid and the smart grid, improving network reliability.

- Increased integration of distributed generation resources.

- Increased security and tolerance to faults.

- Power quality and system reliability.

- Decentralized power management: how to generate an amount of power in a lot of places, rather than a lot of power in one place [2].

The main aim of this paper is to solve problems related to the modeling, control, and power management of distributed generation systems based on the MG's operating modes. Case study system is equipped by a solar system, WECS, and a microturbine system that jointed to system by dc link and choppers to a common link. All of DG's connected to the grid by an inverter. Some loads are connected to MG. Control process explained in islanding and grid tie modes.

System modeling is developed based on the variables for an optimal control of active power flow. Voltage source inverters (VSI) are considered as electronic interface in the MG, and need for new analysis tools. Each DG's and its control strategies are discussed in this article.

\section{Photovoltaic System Description}

Basic implementation method for PV systems by an auxiliary system is shown in Figure 1 [3].

The flexibility of the santerno components allows optimal configuration of the various plants, responding to every kind of need [3]. Reliability, considerable reduction of construction times, ease of maintenance, diagnostics and efficient repairs: these are the essential aspects of the modern photovoltaic plants aimed at constantly guaranteeing of maximizing of energy production. A typical implementation of a MV plant is shown in Figure 2.

Options: 1) fiscal meters; 2) a70-terna compliant interface protection relay; 3) general safety device on the MV board; 4) self- powering system; 5) UPS; 6) premium remote control; 7) Rs485 optical-fiber converter for the connection to a string box; 8) optical-fiber switch LAN for the connection between multiple substations; 9) Anti-theft device; 10) fire device; 11) panic bar on inner side of doors. 


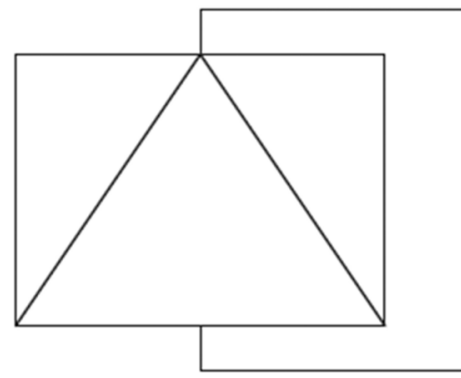

AUXILLRY PHOTOVOLTAIC FIELD
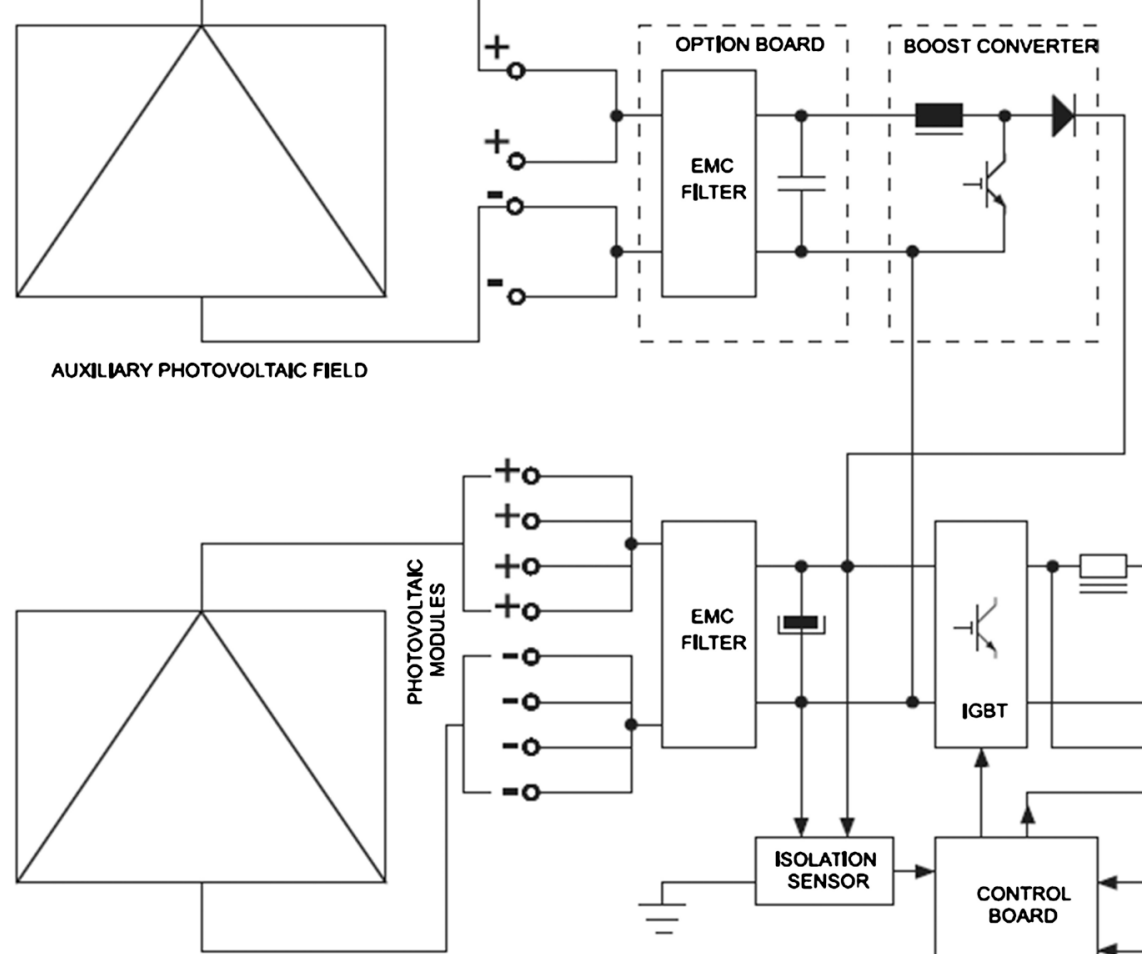

MAIN PHOTOVOLTAIC FIELD
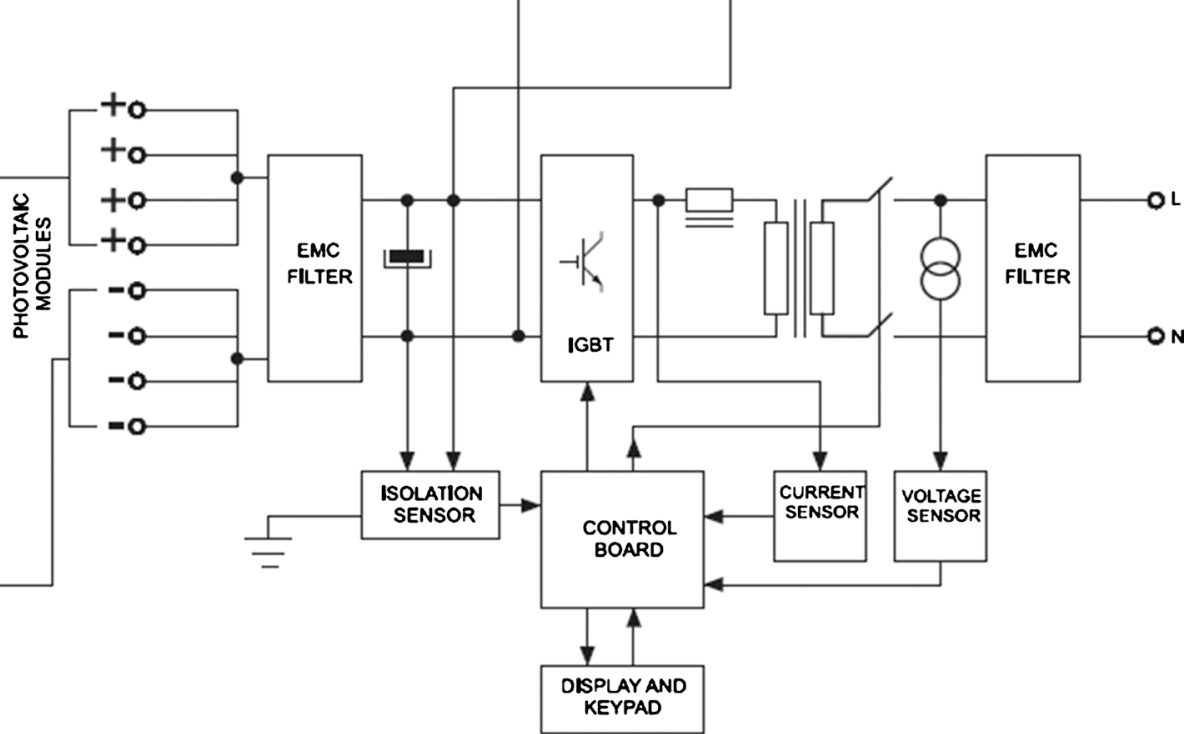

Figure 1. Typical model of photovoltaic system implementation.

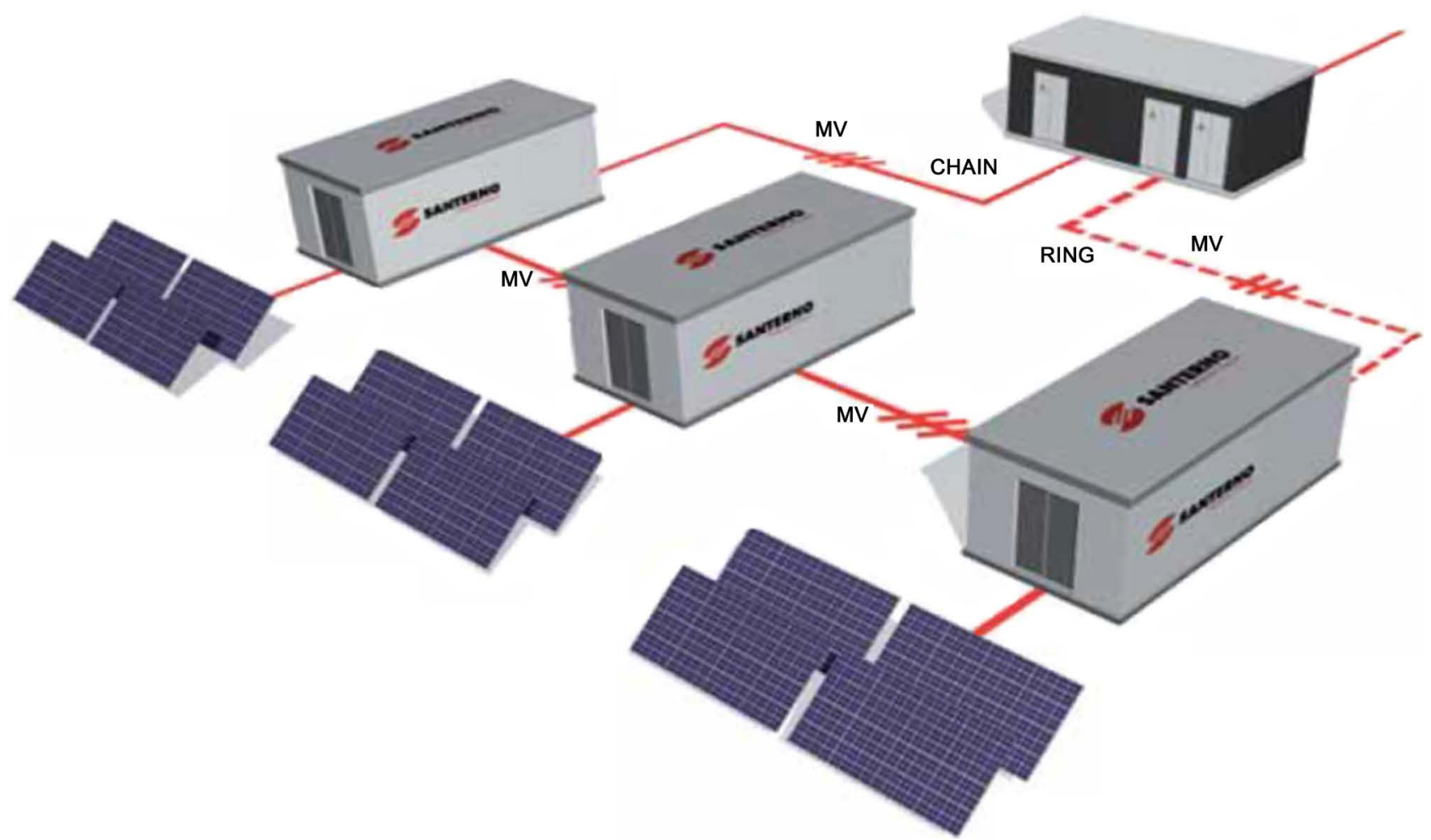

Figure 2. Multiple cabinets with chain or ring configuration [3]. 
Voltage and current waveform of simulated solar panel (Based on Table 1 parameters-Appendix) is shown in Figure 3.

\section{Wind Power Energy Conversion Description}

With a long track record in the industrial and photovoltaic field, santerno designs and manufactures wind turbine inverters of various sizes. All of products are designed for global use and therefore certified according to standards. A wide range of accessories are also available.

Displacement of pitch gearbox, yaw gearbox and generation inverter of WECS is shown in Figure 4.

Technical features of WECS are: high quality design, extremely high reliability, output power factor, top efficiency, maximum operating voltage range, true sin-wave, output grid current, galvanic isolation from grid by means of integrated transformer, freely configurable power curve (32 points) related to turbine PM generator speed. PMSG parameters of WECS have mentioned in Table 2 (Appendix).

Case study control cabinet is shown in Figure 5. Rectifier, inverter, filter and its control blocks are considered.

As it can be seen, output of WECS is shown in Figure 6. Torque-speed, $\mathrm{C}_{\mathrm{p}}-\lambda$ curve, produced power and voltage of DC link of simulated wind power system are displayed. After changing the voltage to a same value by choppers, DC link tied to a mutual inverter for connecting the MGS to grid.

\section{Micriturbine System}

Recently Microturbine (MT) systems have been much applicable because of their small size, relative low cost, repair and cheap maintenance and relatively simple control. Basic model of microturbine system with its output is discussed in [4]. Different dynamic models have been discussed for microturbines by Rowen, Hannet, Saha and Nern for combustion gas turbine [5] [6] [7]. In 1993 mathematical method of gas turbine by Rowen was developed [5]. While in 1993, Prime Mover Working Group by considering the control of speed, acceleration, fuel and

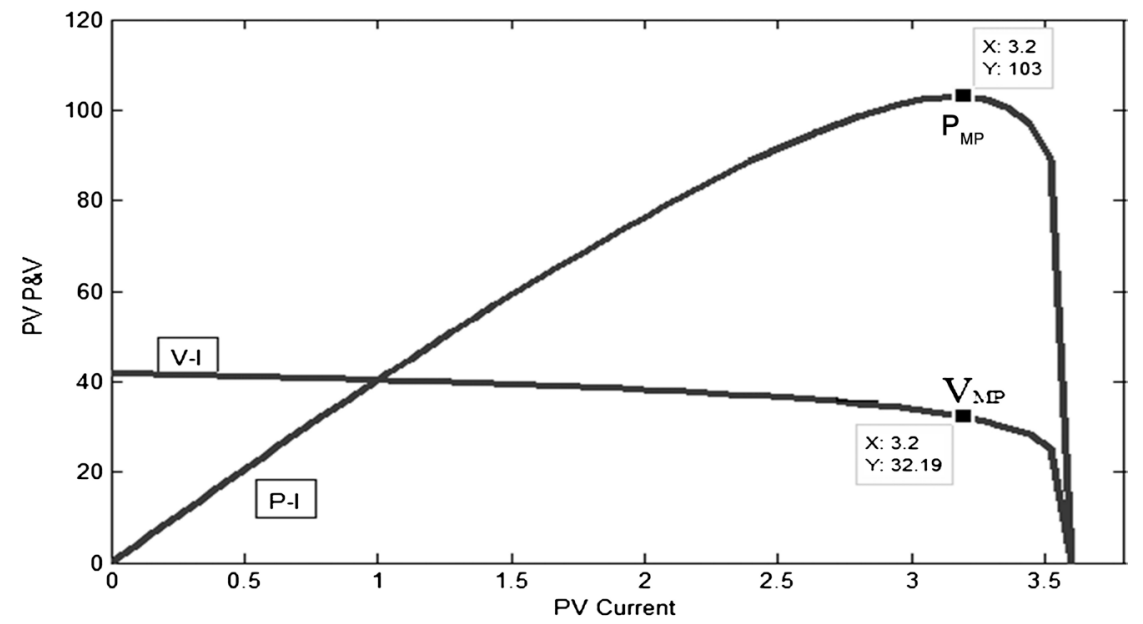

Figure 3. Non-linear characteristics of V-I and P-I. 


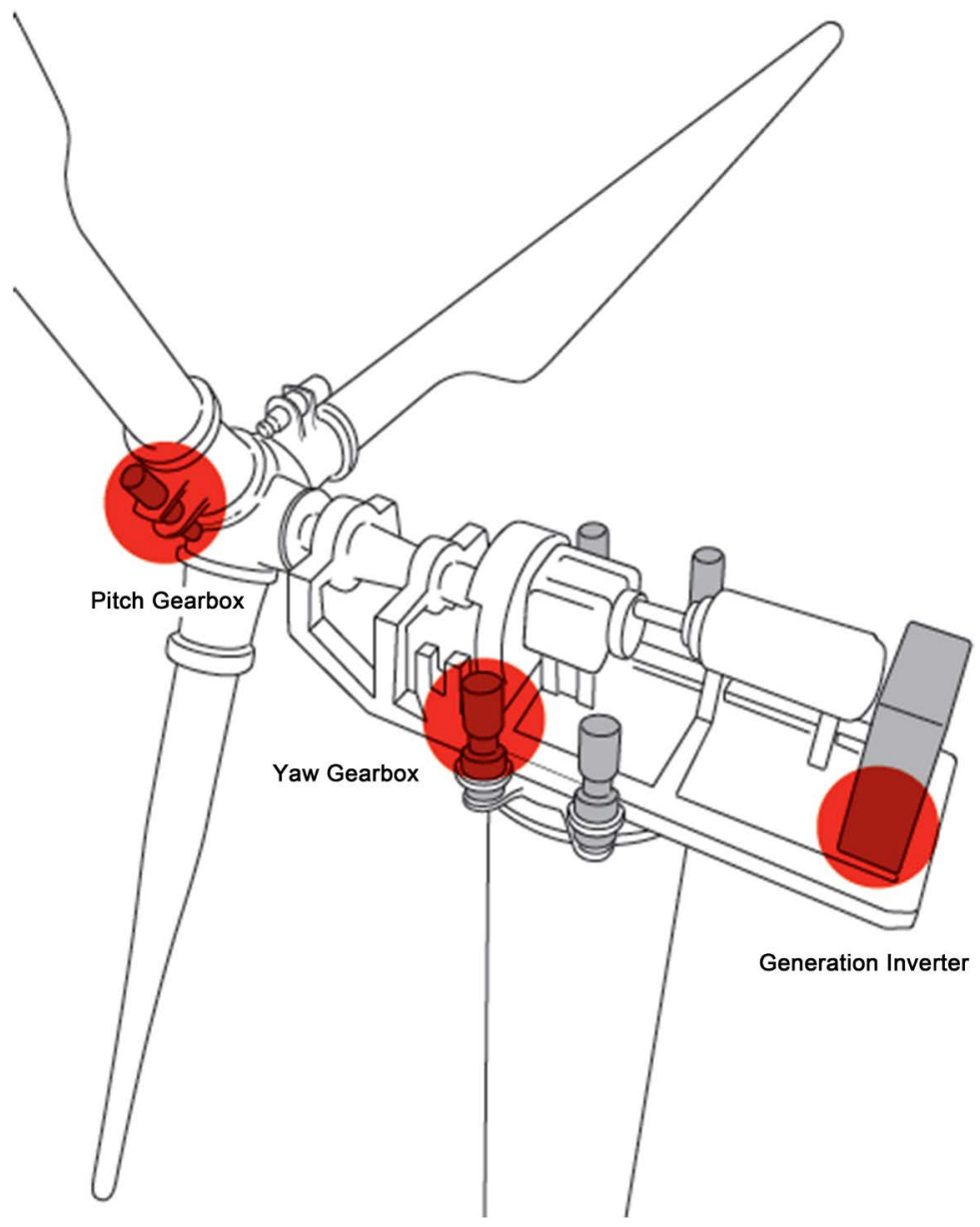

Figure 4. Wind power displacement.

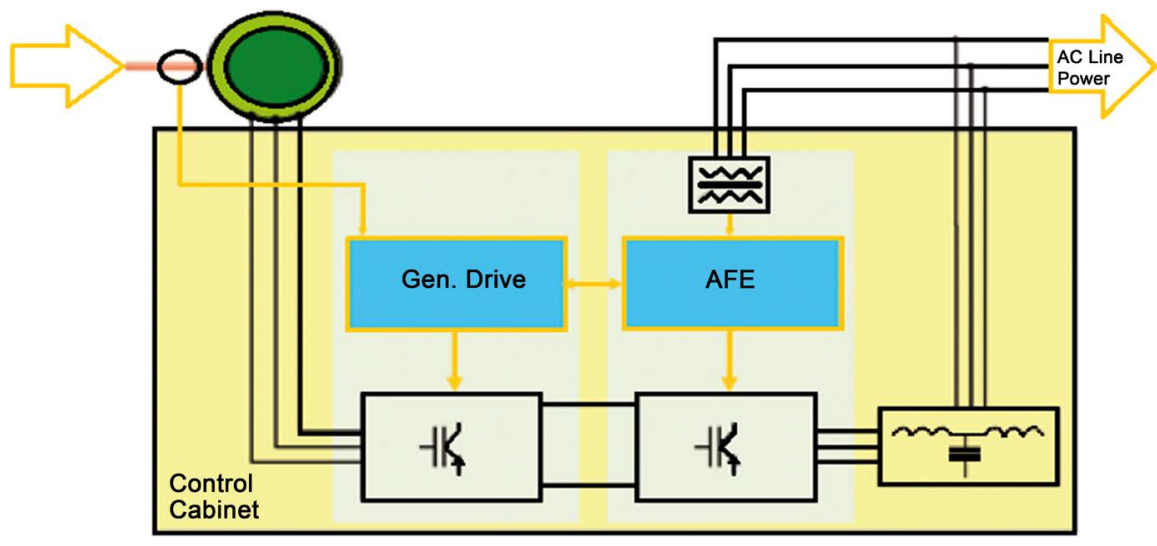

Figure 5. Block diagram of WECS.

temperature made this model wider [6]. MT in this article is a small combustion turbine with an installed capacity 25 to $500 \mathrm{KW}$ and a high rotation speed (between 50,000 to $120,000 \mathrm{rpm}$ ). This model includes the speed governor, acceleration control block, fuel system control and temperature control. Single-shaft turbine model is considered. Power producer with a Permanent Magnet Synchronous Generator (PMSG) has two poles and smooth poles rotor. Because of high speed 

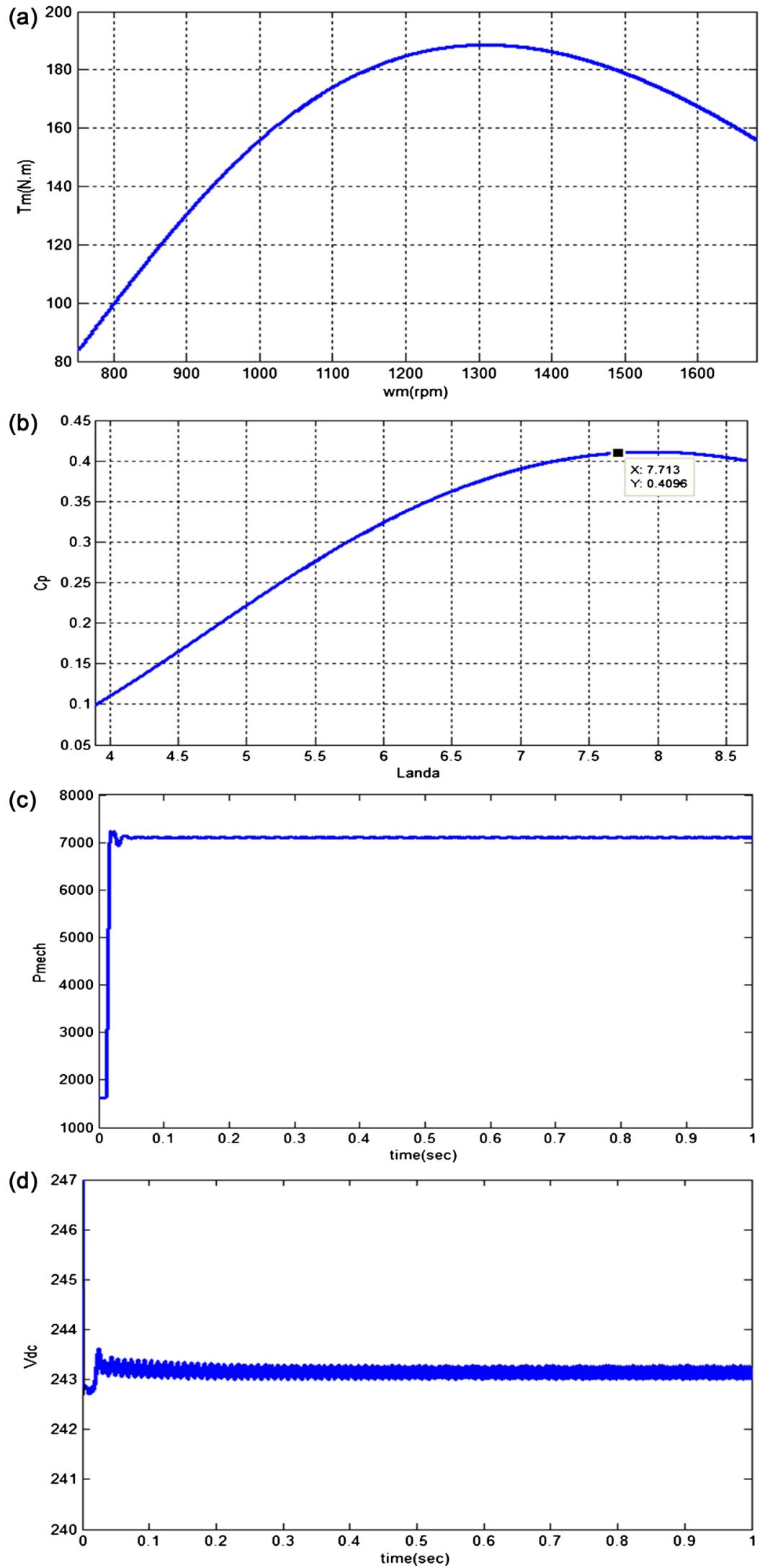

Figure 6. Output of WECS. (a) Torque-Speed characteristics of WT; (b) $C_{p}-\lambda$ curve of WT; (c) Produced mechanical power; (d) DC link Voltage in battery bank terminal. 
shaft, generators of an AC voltage source will be a high frequency (frequency angular higher than 100,000 rad/sec) [7]. Since turbines moves at high speed, so AC generator is a high-frequency generator which cannot be directly coupled the AC grid [8]. One way to model a system of distributed generation MT, based on all classification system are three following separate parts [9] [10]:

Module 1: mechanical system of turbine and fuel.

Module 2: PMSG and AC/DC rectifier and energy storage devices.

Module 3: AC/DC voltage source inverter, PWM controller.

\section{Mechanical Model and MT Control Functions:}

Analysed MT is based on Rowen and Hannet model and dynamic equations of MTS in [5] are investigated.

A typical model of MT system and its electrical connection process is shown in Figure 7.

According to the principle of energy conversion and ignore the inverter losses, total of instantaneous powers in output of AC terminal must be equal to the instant powers in dc terminal like.

$$
V_{d c} I_{d c}=v_{a} i_{a}+v_{b} i_{b}+v_{c} i_{c}
$$

Which $I_{D C}$ and $V_{D C}$ are dc link voltage and current.

\section{System Simulation}

In Figure 8 SIMG is evaluated. Benefits of SIMG compare with three-IMG [4] are: low implementation cost (using one inverter is more inexpensive), simple control (control of single grid-side inverter is simpler rather than three inverters), and maintenance. It's considerable that in DC-side all DG's should have same voltages by choppers (buck and boost). Sensitive loads are parallel in inverter output and joint to the non-sensitive load by a circuit breaker considered in point of common coupling (PCC) and then all of the system is connected to the main grid. Parameters amount are listed in Appendix.

\section{Buck and Boost Design for SIMG}

DG's output DC voltages level are different, hereby choppers should design for assimilated DC voltage surfaces in common bus. By considering the modulation factor (0.8), DC voltage should regulate on 275 volt [11]. By this means, boost chopper for solar system and WECS also buck chopper for microturbine designed.

Design of boost chopper for solar system [11] with consideration of $20 \mathrm{KHz}$ switching frequency, 0.1 ampere current variation and 0.5 volt for voltage variation (input voltage is 35 volt):

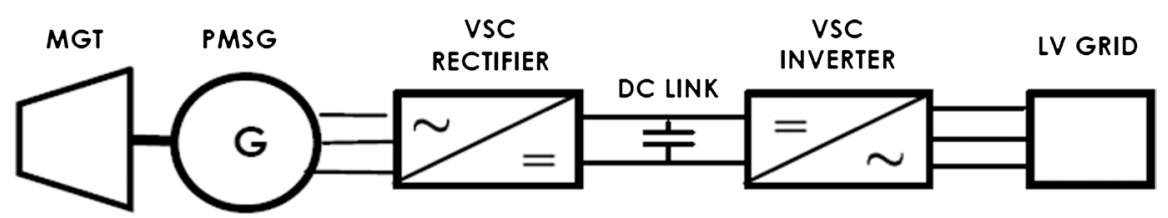

Figure 7. Simplified electrical model of MTS. 


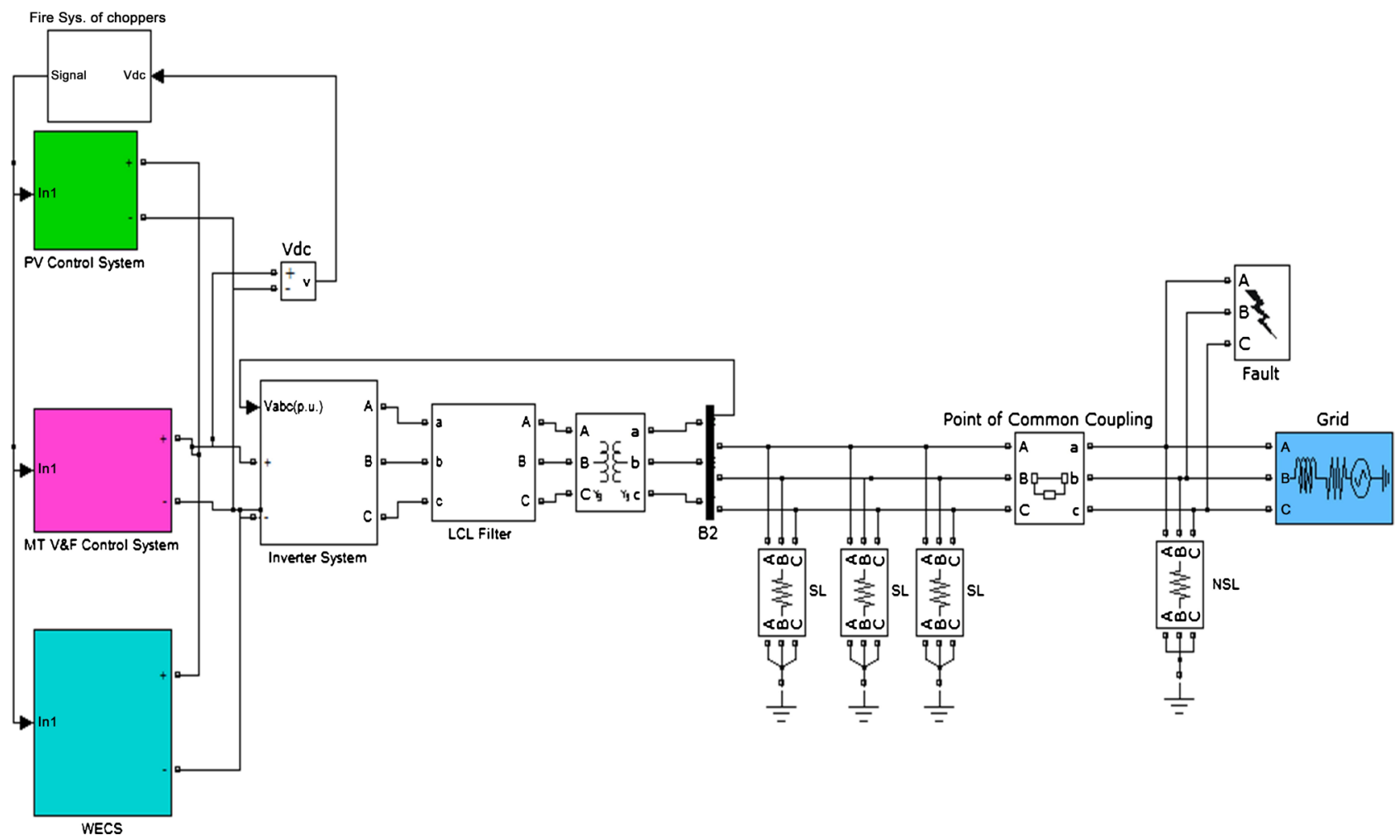

Figure 8. Case study system by single inverter.

$$
\begin{gathered}
L=\frac{V_{s}\left(V_{a}-V_{s}\right)}{f V_{a} \Delta I}=\frac{35(275-35)}{20 \times 10^{3} \times 275 \times 0.1}=15 \mathrm{mH} \\
I_{a}=\frac{P}{V_{a}}=\frac{103}{275}=0.374(\mathrm{~A}) \\
C=\frac{I_{a}\left(V_{a}-V_{s}\right)}{f V_{a} \Delta V_{c}}=\frac{0.374(275-35)}{2 \times 10^{4} \times 275 \times 0.5}=32 \mu \mathrm{F}
\end{gathered}
$$

Boost chopper design for wind power system by considering Equations (1)-(3) is as below (input voltage is 242 volt):

$$
\begin{gathered}
L=\frac{V_{s}\left(V_{a}-V_{s}\right)}{f V_{a} \Delta I}=\frac{242(275-242)}{20 \times 10^{3} \times 275 \times 0.1}=14.5 \mathrm{mH} \\
I_{a}=\frac{P}{V_{a}}=\frac{7100}{275}=25.81(\mathrm{~A}) \\
C=\frac{I_{a}\left(V_{a}-V_{s}\right)}{f V_{a} \Delta V_{c}}=\frac{25.81(275-242)}{2 \times 10^{4} \times 275 \times 0.5}=309 \mu \mathrm{F}
\end{gathered}
$$

Buck chopper design for microturbine system by considering 850 volt for input voltage, $20 \mathrm{kHz}$ switching frequency, $0.5(\mathrm{~V})$ voltage variation, and 0.5 (A) ampere variation:

$$
L=\frac{V_{a}\left(V_{s}-V_{a}\right)}{f V_{s} \Delta I}=\frac{275(850-275)}{20 \times 10^{3} \times 850 \times 0.5}=18.6 \mathrm{mH}
$$




$$
C=\frac{\Delta I}{8 f \Delta V_{c}}=\frac{0.5}{8 \times 2 \times 10^{4} \times 0.5}=6.25 \mu \mathrm{F}
$$

In $0.25 \mathrm{sec}$ MG cuts by CB on PCC because of fault occur in grid, but in 0.42 sec reclosing process befall on PCC after fault abating. MG synchronization process with the grid is accomplished by inverter controller. Transferred power between MG and grid $1 \mathrm{Kw}$ is considered (Figure 9).

In Figure 10, adaption of voltages of MG and grid for one phase is showed. This operation is feasible by grid side applied controller and existent of Phase Loucked Loop (PLL) on it.

Rotor Angle variations of microturbine and wind power generation are shown in Figure 11 and Figure 12 respectively. Microturbine speed variation also illustrated in Figure 13.

THD of SIMG in grid tie and islanding modes are shown in Figure 14 and Figure 15. Achieved values from simulation are in standard range. By a simple comparison between single inverter and three inverters MG concluded that THD of SIMG is less than THD of three-IMG. This is a benefit of SIMG than three-IMG.

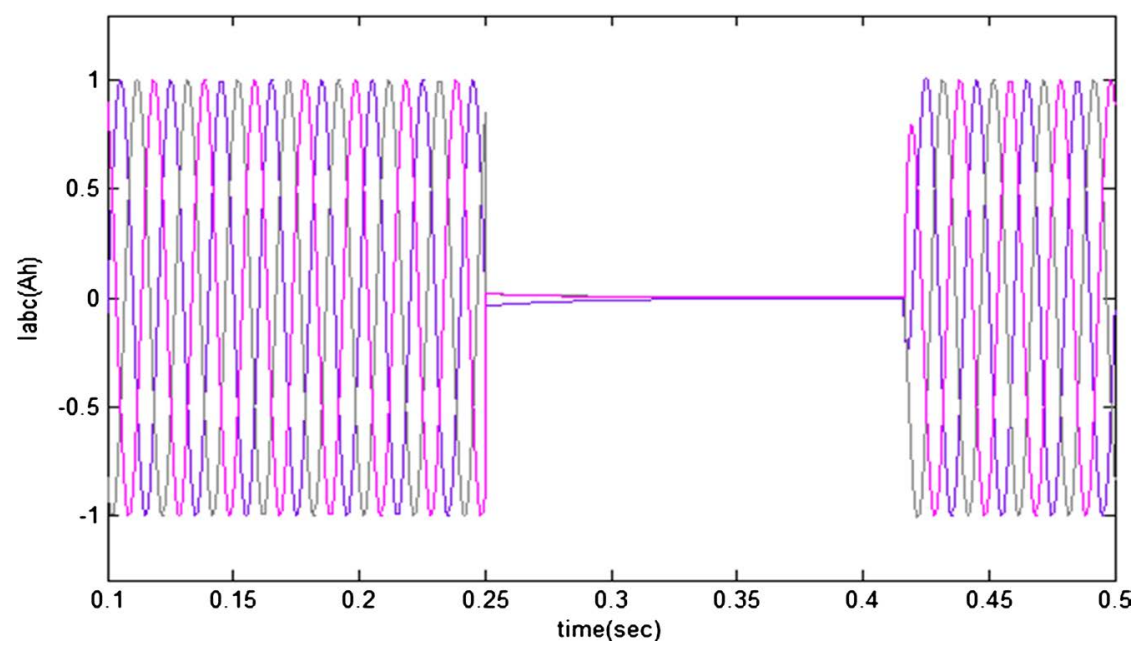

Figure 9. Line three phase current (transferred current between MG and grid).

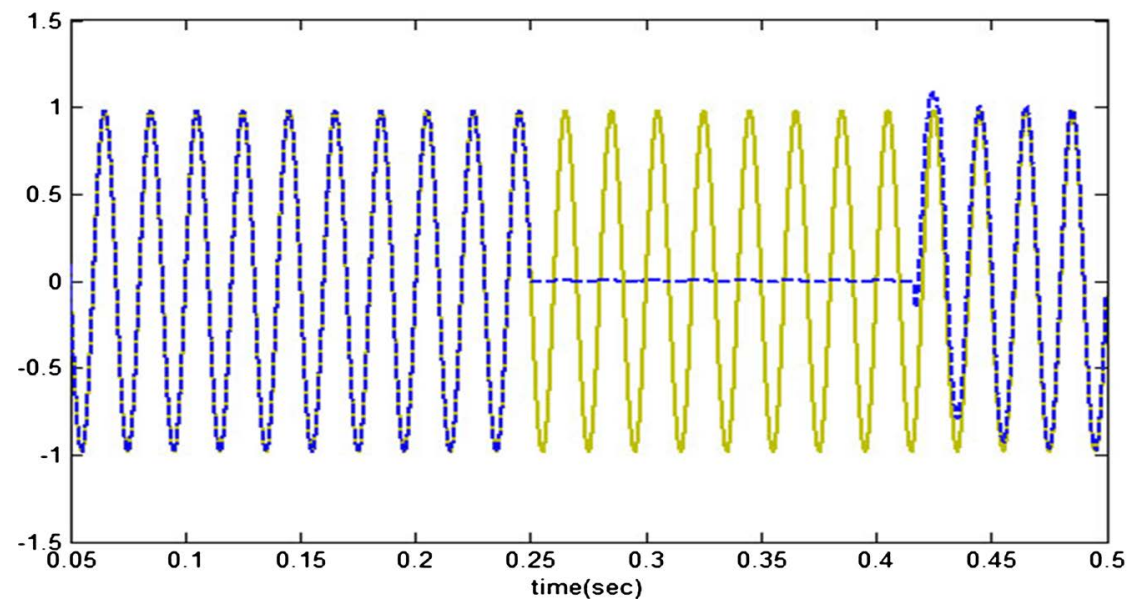

Figure 10. Current adaption between grid and MG. 


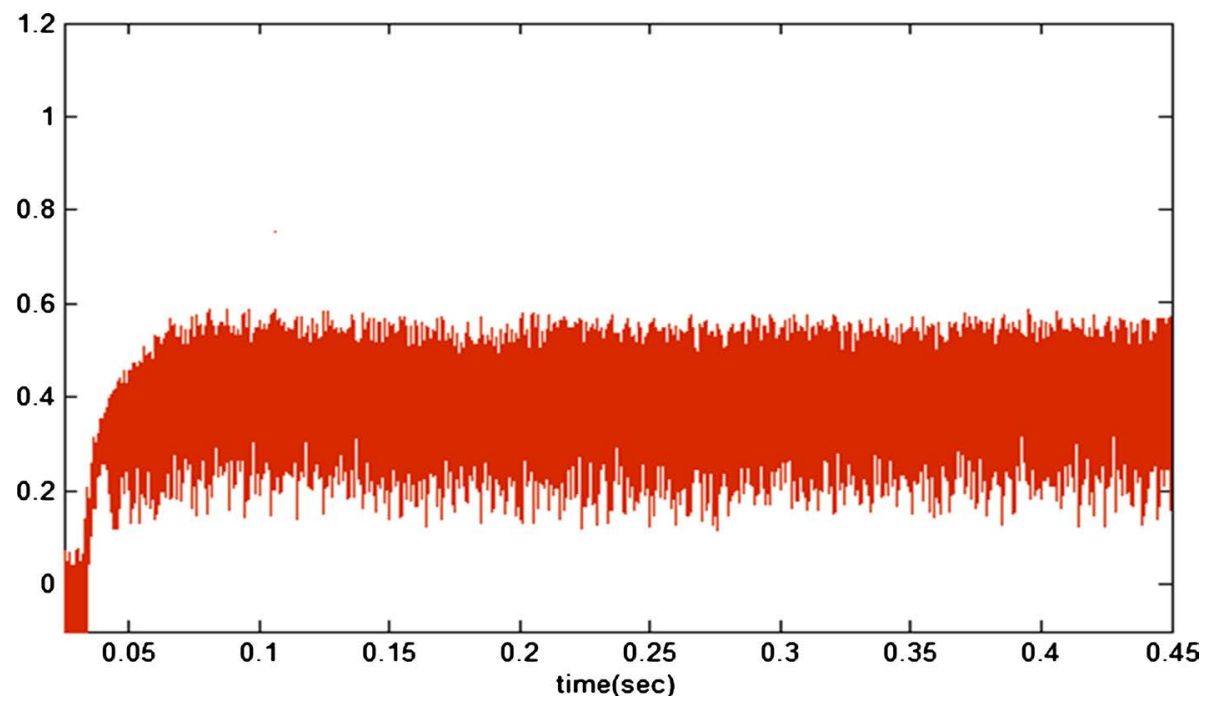

Figure 11. Rotor angle variation in microturbine generators by radian.

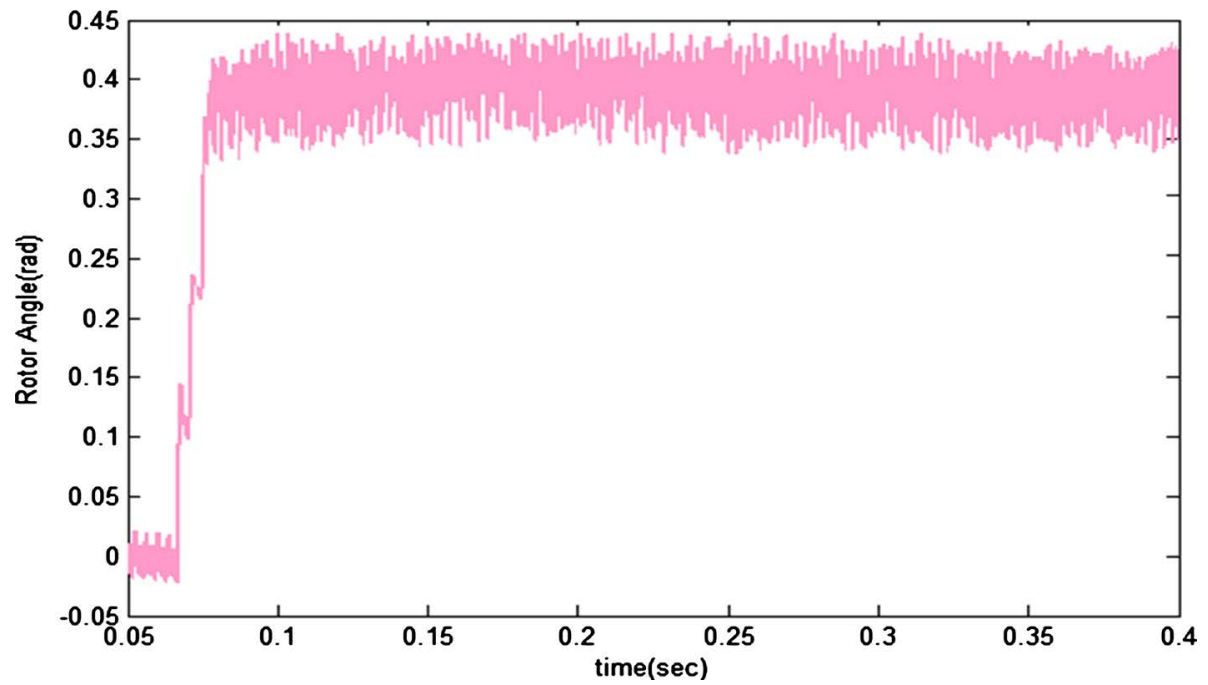

Figure 12. Rotor angle variation in wind power generators by radian.

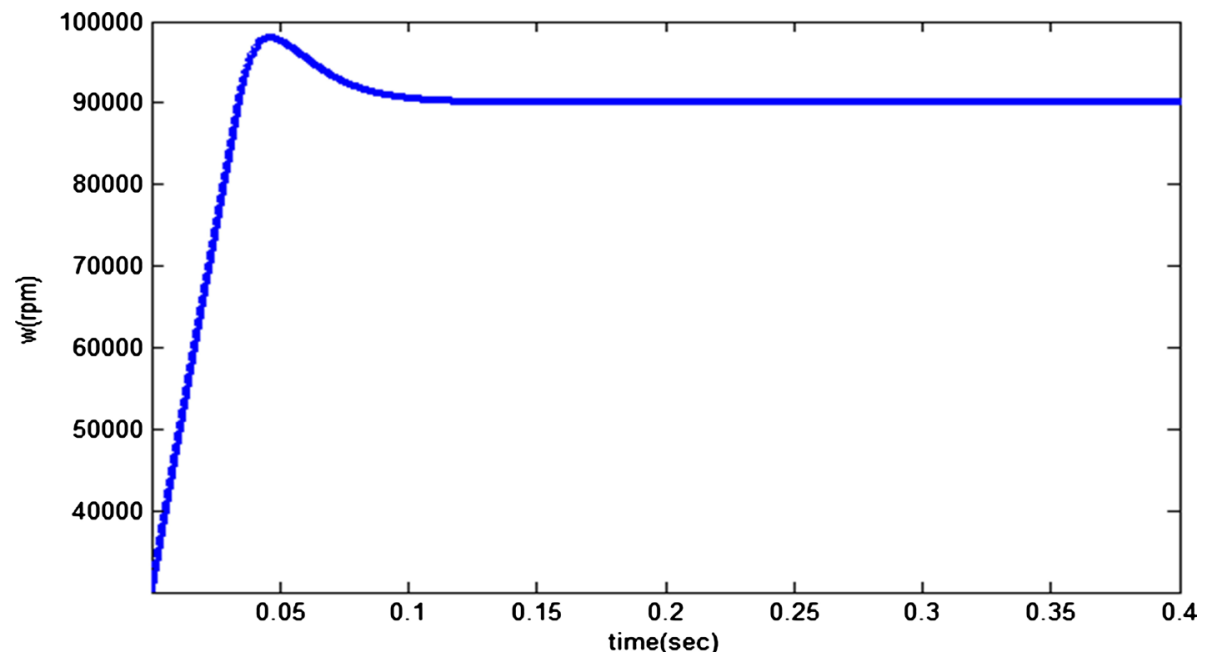

Figure 13. Microturbine speed on time unit. 


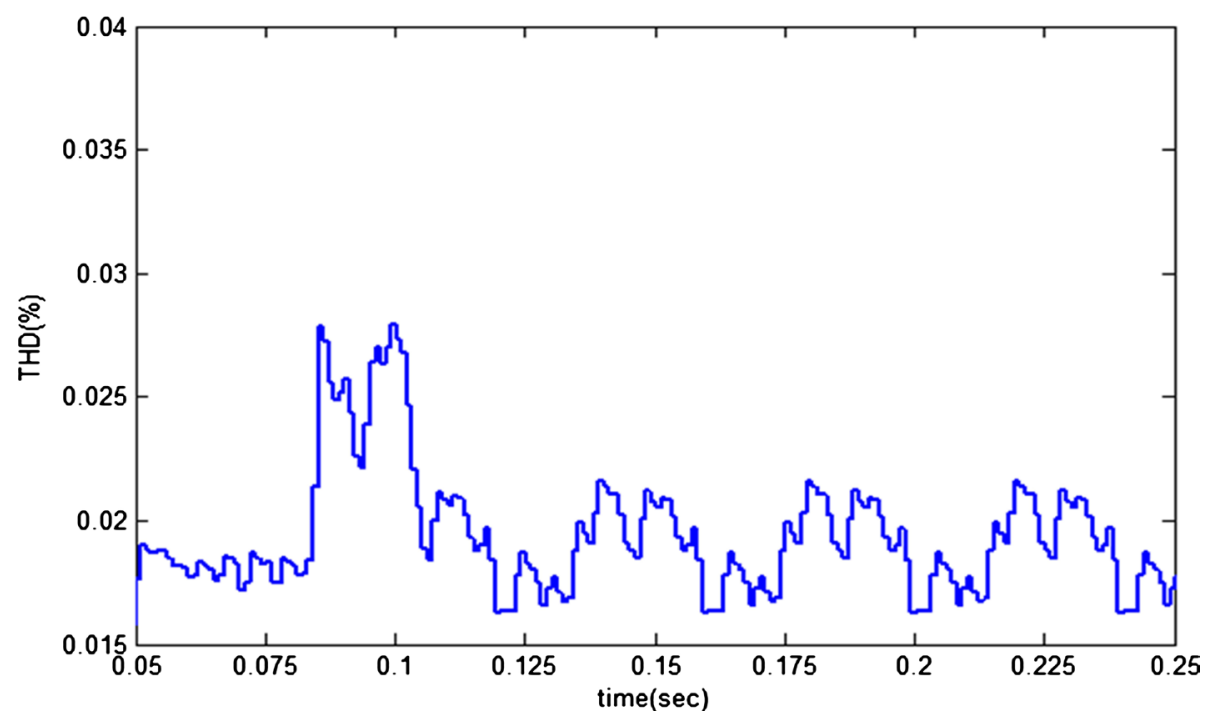

Figure 14. Total harmonic distortion of SIMG for grid tie mode.

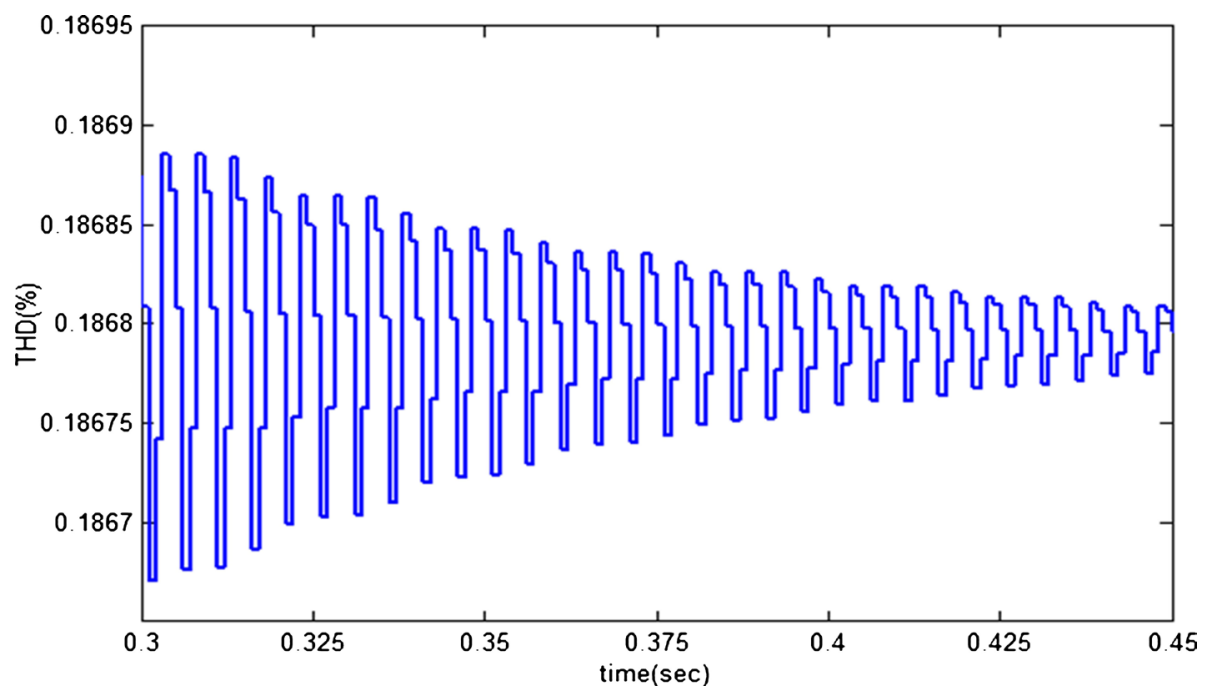

Figure 15. Total harmonic distortion of SIMG for islanding mode.

\section{Conclusion}

In this paper, simulation and analysis of a typical MG system has been investigated. For this system, decentralize control strategy with one inverter in grid side discussed and simulated. Practical implementation method for the case study system by santerno production has been reviewed. Sensitive loads are for SIMG and non-sensitive loads have been considered for the grid. In disconnecting time of MG from grid by PCC (exerted fault detector), SIMG operated in autonomous mode. Each DG's produced power applied to sensitive loads. After fault clearance, grid and MG reconnect again and micro smart grid continues to operation. Buck and boost converters are designed to have same voltages at inverters input. In DC link for each DG, battery bank applied for storing the excess energy of DG's. Reliability of grid has increased by storage devices. 


\section{Conflicts of Interest}

The authors declare no conflicts of interest regarding the publication of this paper.

\section{References}

[1] (2006) European Smart Grids Technology Platform. Printed on White Chlorine, ISBN 92-79-01414-5.

[2] Quintero, J.C.V. (2009) Decentralized Control Techniques Applied to Electric Power Distributed Generation in Microgrid. Doctorate Thesis, Universitat Plitecnica De Catalunya.

[3] (2012) Solar and Wind Energy Handbook. Santerno-Carraro Group, Italy.

[4] Moradian, M., Tabatabaei, F. and Moradian, S. (2013) Modeling, Control \& Fault Management of Microgrids. Smart Grid and Renewable Energy, 4, 99-112. https://doi.org/10.4236/sgre.2013.41013

[5] Rowen, W.I. (1983) Simplified Mathematical Representations of Heavy Duty Gas Turbines. Journal of Engineering for Power, 105, 865-869. https://doi.org/10.1115/1.3227494

[6] Hannet, L.N. and Khan, A. (1993) Combustion Turbine Dynamic Model Validation from Tests. IEEE Transactions on Power Systems, 8, No. 1.

[7] Saha, A.K., Chowdhury, S., Chowdhury, S.P. and Crossley, P.A. (2009) Modeling and Performance Analysis of a Microturbine as a Distributed Energy Resource. IEEE Transactions on Energy Conversion, 24, No. 2.

[8] Working Group on Prime Mover and Energy Supply Models for System Dynamic Performance Studies. (1994) Dynamic Models for Combined Cycle Plants in Power System Studies. IEEE Transactions on Power Systems, 9, 1698-1708. https://doi.org/10.1109/59.336085

[9] Zamora, I., San Martin, J., Mazon, A., San Martin, J. and Aperribay, V. (2005) Emergent Technologies in Electrical Micro-generation. International Journal of Emerging Electric Power Systems, 3, No. 2.

[10] Ong, C.-M. (1998) Dynamic Simulation of Electric Machinery Using Matlab/Simulink. Prentice Hall, Upper Saddle River. 


\section{Appendix}

Carrier frequency in VMPPT PWM generator, $3000 \mathrm{~Hz}$ and in grid-side controller, $5000 \mathrm{~Hz}$, boost converter parameters: $L=0.0034 \mathrm{H}, C=0.00561 \mathrm{~F}$. PI coefficients in grid-side controller: $K_{p V_{d c}}=0.05, K_{i V_{d c}}=3, K_{p I_{d}}=2.5$, $K_{i I_{d}}=700, K_{p I q}=2.5, K_{i I q}=700$.

Table 1. Values and coefficients used in PV cell.

\begin{tabular}{ccc}
\hline Current Temp. Coefficient & $\alpha=0.002086$ & {$\left[\mathrm{~A} /{ }^{\circ} \mathrm{C}\right]$} \\
Voltage Temp. Coefficient & $\beta=0.0779$ & {$\left[\mathrm{~V} /{ }^{\circ} \mathrm{C}\right]$} \\
Reverse Saturation Current & $I_{0}=0.5 \times 10^{-4}$ & {$[\mathrm{~A}]$} \\
Short Circuit Cell Current & $I_{p h}=I_{S C}=0.5 \times 10^{-4}$ & {$[\mathrm{~A}]$} \\
Cell Resistance & $R_{S}=0.0277$ & {$[\Omega]$} \\
Cell Material Coefficient & $\lambda=0.049$ & {$[1 / \mathrm{V}]$} \\
\hline
\end{tabular}

Table 2. Synchronous generator parameters amounts.

\begin{tabular}{ccc}
\hline Parameters & Amount & Unit \\
\hline Stator phase resistance $R_{s}$ & 0.0485 & $\Omega$ \\
Stator inductances $\left(L_{d}, L_{q}\right)$ & 0.395 & $\mathrm{mH}$ \\
Inductive flow by permanent magnet & 0.1194 & $\mathrm{~Wb}$ \\
Moment of inertia $(\nearrow)$ & 0.0027 & $\mathrm{~kg} \cdot \mathrm{m}^{2}$ \\
Nominal power & 14 & $\mathbf{k w}$ \\
Pairs of poles $(P)$ & 4 & - \\
\hline
\end{tabular}

